EDITORIAL

\title{
Impact of COVID-19 pandemic on higher education in Japan: Transition to online education and challenges in experiential pharmacy practice
}

\author{
Ichiro Matsuoka \\ College of Pharmaceutical Sciences, Matsuyama University, Japan
}

\author{
Correspondence \\ Ichiro Matsuoka \\ College of Pharmaceutical Sciences \\ Matsuyama University \\ Bunkyo-Cho-4-2 \\ Matsuyama \\ Ehime \\ 790-8578 Japan \\ imatsuok@q.matsuyama-u.ac.jp
}

The COVID-19 pandemic has impacted all aspects of human life, including
pharmacy education worldwide. This article depicts how the COVID-19 pandemic
has impacted higher education in Japan with a focus on two topics: the transition
to online education and the challenges faced in experiential pharmacy practice.
In both topics, the sharing of information among educators and stakeholders,
from students to governmental ministries, played vital roles in keeping the
programme delivery as normal as possible during the pandemic. Insights gained
from experience during the pandemic should offer a basis for the robust and
versatile framework of tomorrow's pharmacy education.

\section{Introduction}

As a luxury cruise ship with a group of infected people onboard berthed alongside a pier at the port of Yokohama in early February 2020, Japanese society suddenly became fully aware of the seriousness of the COVID-19 hazard. In a sense, it was a less hazardous timing for the academic calendar in Japan. In almost all universities in Japan, the school year starts with the spring term (April-September), which is followed by the autumn term (October-March). By the time the number of daily infections of COVID-19 started to rise sharply in Japan in late March, university examinations and processes of credit recognition were almost over. The national pharmacist licensing examination for the graduates of the six-year-B.Pharm. programme had been conducted without trouble in late February, and the numbers of applicants and successful examinees were almost the same as in the previous year (respectively, applicants/successful examinees/year: 14,002/9,845/2020, $14,035 / 10,079 / 2019)$. However, graduation as well as entrance ceremonies were cancelled in most universities as cautionary measures.

After the lessons learnt from the cruise ship and other situations, the Japanese Ministry of Health (MHLW) began to advise citizens to avoid the 'three Cs' (which stand for closed spaces, crowded places, and close-contact settings) as an alternative phrase to 'social distancing' (Ministry of Health, 2020a, 2020b). The Education Ministry of Japan (MEXT) also sent out notifications to universities on 24th March about the avoidance of the three Cs on the university campus, the possible implementation of remote classes (online teaching), and flexible measures for the credit recognition (Ministry of Education, 2020). Accordingly, leading universities started to set up systems of remote classes as early as mid-February, while keeping the academic calendar as normal as possible. However, for most Japanese universities, the experience with remote classes was quite limited at that time. 


\section{Transition to remote classrooms}

As the number of domestic infections continued to rise, a nation-wide state of emergency was declared on 7th April (the cumulative number of domestic infections was 4,393). However, the Japanese government did not take legally binding "lockdown"-like measures but took strategies based on advice and self-restraints. Accordingly, most universities voluntarily responded to the government advice and closed their campuses, postponed the start of spring term until the beginning of May (most universities) or the end of May (some universities), and worked hard on setting up a university-wide remote-class system (Table I \& II).

Table I: Response of Japanese universities to COVID-19 pandemic (as of 12th May 2020)

\begin{tabular}{lccc}
\hline & \multicolumn{3}{c}{ Start classes as previous year } \\
\hline & $\begin{array}{c}\text { Postponed } \\
\text { start of } \\
\text { classes }\end{array}$ & $\begin{array}{c}\text { Will use or } \\
\text { considering } \\
\text { distance- } \\
\text { learning }\end{array}$ & $\begin{array}{c}\text { Do not use } \\
\text { distance- } \\
\text { learning }\end{array}$ \\
\hline National University & $78(90.7 \%)$ & $8(9.3 \%)$ & $0(0.0 \%)$ \\
Municipal University & $87(82.9 \%)$ & $14(13.3 \%)$ & $0(0.0 \%)$ \\
Private University & $715(87.0 \%)$ & $86(10.5 \%)$ & $1(0.1 \%)$ \\
\hline Technical College & $50(87.7 \%)$ & $7(12.3 \%)$ & $0(0.0 \%)$ \\
\hline (Overall) & $930(86.9 \%)$ & $\mathbf{1 1 5 ( 1 0 . 7 \% )}$ & $\mathbf{1 ( 0 . 1 \% )}$ \\
\hline
\end{tabular}

Table II: Spread of distance learning among Japanese universities (as of 1st June 2020)

\begin{tabular}{lccc}
\hline & $\begin{array}{c}\text { Face-to-face } \\
\text { classes only }\end{array}$ & $\begin{array}{c}\text { Combination of } \\
\text { face-to-face } \\
\text { \& distance- } \\
\text { learning }\end{array}$ & $\begin{array}{c}\text { Distance } \\
\text { learning } \\
\text { classes only }\end{array}$ \\
\hline National University & $0(0.0 \%)$ & $23(26.7 \%)$ & $63(73.3 \%)$ \\
Municipal University & $5(5.0 \%)$ & $29(29.0 \%)$ & $66(66.0 \%)$ \\
Private University & $96(11.7 \%)$ & $256(31.1 \%)$ & $471(57.2 \%)$ \\
Technical College & $2(3.5 \%)$ & $14(24.6 \%)$ & $41(71.9 \%)$ \\
\hline (Overall) & $103(9.7 \%)$ & $\mathbf{3 2 2 ( 3 0 . 2 \% )}$ & $641(60.1 \%)$ \\
\hline
\end{tabular}

During this period, the National Institute of Informatics (NII) played an important role in the insemination of ideas, methods, and practice of the remote class for all universities in Japan. Thus, NII has organised a bi-weekly series of 'Cyber Symposia on University Remote Class' since 26th March, which is still continuing today (National Institute of Informatics, 2020). In each symposium, a number of leading universities have provided varieties of case reports of remote classes, such as synchronous/ asynchronous methodologies, compilations of IT vendors (Zoom, Teams, WebEx, Moodle etc.), applications in different types of class settings (lectures, discussions, experimental practice etc.), faculty developments on remote teaching, and responses from both students and faculties. MEXT has also participated in each symposium to provide the latest information about the governmental measures to keep university education going during the COVID-19 crisis as well as update statistics of nationwide university education. Experiences in foreign universities are also conveyed. These series of symposia have become a big milestone for university leaders and teachers implementing individual teaching systems at their own institutions. Consequently, a variety of information was shared in the Cyber Symposia. Some examples with experience obtained from the authors' pharmacy school are outlined here.

It was soon revealed that students noticed several advantages of the online classroom such as the instancy at home without commuting, the convenience to grasp information in a digital manner instead of writing in notebooks, and the easier communication with their teachers through online chatting. Interestingly, the same group of students pointed out a variety of disadvantages of online classrooms, such as the instability of Wi-Fi connections, a feeling of continuing social isolation without face-to-face communication among students, and a vagueness of learning, mainly arising from nonsynchronous classrooms such as on-demand lectures without any feedback. The handling of experimental practice classes (e.g. biochemistry experiment practice class) was split between universities; some universities postponed the experimental practice classes until the autumn term, while other universities went on with experimental practice classes in the real setting with special considerations on the avoidance of the three Cs, such as splitting into smaller sizes of class at a time with increased ventilation.

As spring term proceeds, a mental health problem of the first-year students has become another important issue. Since the entrance exams were held before April, the first-year students in many universities have never walked into their new campus where their future professionalism is nurtured and have never talked to any classmates face-to-face. The importance of a feeling of belonging for first-year students is now widely recognised. Hence, it is 
highly recommended that first-year students should be given appropriate opportunities for orientation, such as a small-group campus tour for learning about the history of their university and real-life chatting with their seniors and mentors over their new campus life in an intimate environment, of course with consideration on the avoidance of the three Cs. Further, small group discussions are a powerful method for nurturing students' abilities in many aspects. Hence, the authors set up an online programme of clinical, case-based ethics debate sessions in healthcare ethics class by using the breakout room feature of Zoom. At the beginning of the online class, the handling of eight person-groups, each distributed in the total of 15 breakout rooms, which would continue over four weeks, seemed very complex and difficult. But in the end, the authors found that the students were really enjoying the experience of an online debate from their socially isolated quarantine environments.

During this pandemic, the collection of students' tasks and its evaluation became very easy and popular with the help of learning management systems such as Blackboard and Moodle. So, for the reason of evaluation, teachers began to impose task assignments after each online session (mostly lectures) which created too much of a burden for students and led to the loss of their concentration. It is noteworthy that a typical timetable of an undergraduate course in Japanese universities, including B.Pharm., contains a very large number of lectures per week (ten and more is not unusual).

As the end of spring term approached, many universities opened their campus to students (the state of emergency was lifted for the whole country on 25th May) and the "new normal" of university education for the autumn term and beyond became a main focus in the Cyber Symposia. According to the survey of MEXT, as of 11th September $(n=1060)$, about one third of Japanese universities are planning to resume the autumn term in almost all face-to-face classes again. However, the rest of the universities expect to continue online teaching with varying degrees. At this stage, MEXT, urged by students' voice, had become encouraging universities to resume the face-to-face education as much as possible depending on the situation. Japanese universities have now started to think that proper use of online methods and their improvement should contribute not only to the risk management during the pandemic but to the improvement of the quality of learning and education themselves. In the recent Cyber Symposia, several leading universities provided models of hybrid teaching in which online sessions and real face-to-face sessions are combined in different ways, such as the 'hyflex' model (students can choose either online or real classroom teaching for the same single session, depending on their personal condition) and the 'blended' model (online and real sessions are combined in an alternating or sequential manner to maximise the efficiency of learning). Furthermore, trial studies of online experiment practice classes using hybrid methods were also shown.

Finally, it is noteworthy that the groups of digital native students also gave presentations in the Cyber Symposia on their efforts in facilitating the implementation of the remote classroom, such as the provision of the online chat support for both the students and teachers who are in need of various types of help in adapting to the remote classroom. This kind of cooperation between students and teachers would also shape a new era of post-COVID-19 education.

\section{Challenges in pharmacy/hospital practice}

In the Japanese six-year pharmacy education system (B.Pharm.), which is based on the national model core-curriculum, experiential activities play a vital role in the development of technical skills and professionalism of the pharmacist (The Pharmaceutical Society of Japan, 2018). Following the short hands-on training (early exposure to the profession) in early years (usually one day one week in first or second year), fifth-year pharmacy students go on an 11 weeks practice at a community pharmacy and then an 11 weeks practice at a hospital pharmacy in two of the four terms during the fifth year. Although these practical activities are essential parts of B.Pharm. education, they are operated in collaboration with, or operated substantially by, community and hospital pharmacies. Because of the increased risk of a COVID-19 infection, many universities had to cancel or postpone the early exposure activities at medical facilities during the period of the state of emergency or throughout the spring term.

As for the $11+11$ weeks pharmacy practices in the fifth year of the B.Pharm., two Japanese professional bodies of pharmacists, the Japan Pharmaceutical Association (JPA) and the Japan Society of Hospital Pharmacy (JSHP), in collaboration with other academic bodies, played important roles such as providing guidelines for the student practice at medical facilities during the COVID-19 pandemic. As the state of emergency was declared, JPA started to provide essential advice for the 11-weeks practice at community pharmacies, such as frequent and mutual consultation between the university and the pharmacy on the flexible amendment of tasks and evaluations and cares for the intern students, including the assessment of physical conditions. JSHP also provided 
similar advice on the practice at hospital pharmacies, including the classification of practice levels from the normal level to highly restricted levels, according to the level of the spread of the COVID-19 infection. However, the situation of the spread of the virus infection varies from prefecture to prefecture and especially from urban areas to rural areas. Therefore, the handling of the student's practice had to be addressed on a regional basis at branches of the Council of Pharmaceutical Education (regional pharmacy practice adjustment centres), and sometimes on an individual facility basis. As a result, the 11 weeks community pharmacy practice during the second term of the practice calendar (May-August) was operated almost safely on a national scale with sporadic cancellations by facilities in critical conditions. Online learning methods were partially incorporated, especially in urban areas where the risk of the infection was higher.

However, pharmacy practices at hospitals had to face different kinds of challenges such as a higher risk of infection in the patient-facing tasks at hospital wards and the increased burden of hospital pharmacists (preceptors) due to pandemic. Although every possible measure was taken for the intern students not to become a source of infection, many hospitals had to cancel or postpone the accommodation of intern students until the third term (August-November) or later. At the same time, however, many hospitals partially (up to six weeks) replaced the patient-facing and non-facing tasks with relevant online learning tasks, according to the guideline of JSHP, and tried to keep the hospital practice going as normal as possible.

Following the revision of the core curriculum in 2015, a standardised Pharmacy Practice WEB System was implemented at each pharmacy school nationwide in Japan. So far, this WEB System has offered an efficient platform of journal keeping and portfolio-building for intern students, and this system has also been used as a communal platform of evaluation by both preceptors at facilities and teachers at pharmacy schools. Consequently, one can recognise that this WEB System is serving as an important tool of information sharing and keeping the pharmacy practice during the COVID-19 crisis as normal as possible.

\section{Conclusion}

Since the framework of a six-year B.Pharm. education system was established in 2006, improvement of its quality toward the new direction of competency development of pharmacists has been a long-standing agenda among pharmacy schools in Japan. As the COVID-19 pandemic continues to affect all aspects of human life, everyone experienced things to change very quickly and drastically. Pharmacy intern students practicing on-site during the pandemic should have developed a vivid awareness of the irreplaceable professional value of pharmacists. Pharmacy educators have also managed to acquire skills necessary for the novel style of education in such a short period of time. In the coming years, a reflection of Japan's current education system with all the insights gained from experiences during the COVID-19 crisis should provide a new basis for a robust and versatile framework of education. This is just the beginning of a journey toward the next stage of pharmacy education.

\section{Acknowledgement}

The author is grateful to Dr Shinji Akiyama, Dr Takatoshi Sakamoto, and Dr Takumi Yamaguchi for the sharing of information concerning the regional pharmacy practice activities during the pandemic.

\section{Post-script}

A second state of emergency was declared on 7th January 2021 over the Tokyo metropolitan area and it was expanded to other large urban areas on 13th January 2021. Since university classrooms have not been proven to be major sites of COVID-19 infection, governmental measures on university education are largely unchanged so far.

\section{References}

Ministry of Education (MEXT) (2020). Information on the MEXT's measures against COVID-19. Available at: https://www.mext. go.jp/en/mext_00006.html

Ministry of Health (MHLW) (2020a). COVID-19 Information update from the ministry of health, labor, and welfare. Available at: https://www.mhlw.go.jp/stf/seisakunitsuite/bunya/newpage 000 $\underline{32 . h t m l}$

Ministry of Health (MHLW) (2020b). Avoidance of Three Cs (MHLW). Available at: https://www.mhlw.go.jp/content/ 10900000/000615287.pdf

The National Institute of Informatics (NII) (2020). The Cyber Symposia on University Remote Teaching. Available at: https://www.nii.ac.jp/event/other/decs/

The Pharmaceutical Society of Japan (PSJ) (2018). Model core-curriculum for pharmacy education. Available at: https://www.pharm.or.jp/kyoiku/pdf/corecurri eng180426.pdf 